\title{
Instructional Moves that Increase Chances of Engaging All Students in Learning Mathematics
}

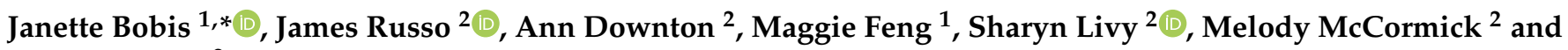 \\ Peter Sullivan $^{2}$ \\ 1 Sydney School of Education and Social Work, University of Sydney, Sydney, NSW 2006, Australia; \\ mfen5873@uni.sydney.edu.au \\ 2 Faculty of Education, Monash University, Clayton, VIC 3800, Australia; james.russo@monash.edu (J.R.); \\ ann.downton@monash.edu (A.D.); sharyn.livy@monash.edu (S.L.); melody.mccormick@monash.edu (M.M.); \\ peter.sullivan@monash.edu (P.S.) \\ * Correspondence: janette.bobis@sydney.edu.au
}

check for

updates

Citation: Bobis, J.; Russo, J.; Downton, A.; Feng, M.; Livy, S.; McCormick, M.; Sullivan, P. Instructional Moves that Increase Chances of Engaging All Students in Learning Mathematics. Mathematics 2021, 9, 582. https://doi.org/ $10.3390 /$ math 9060582

Academic Editors: Jarmila Novotná and Alena Hošpesová

Received: 18 February 2021

Accepted: 8 March 2021

Published: 10 March 2021

Publisher's Note: MDPI stays neutral with regard to jurisdictional claims in published maps and institutional affiliations.

Copyright: (c) 2021 by the authors. Licensee MDPI, Basel, Switzerland. This article is an open access article distributed under the terms and conditions of the Creative Commons Attribution (CC BY) license (https:// creativecommons.org/licenses/by/ $4.0 /)$.

\begin{abstract}
Despite the construct of challenge being recognized as an essential element of mathematics instruction, concerns have been raised about whether such approaches benefit students with diverse academic needs. In this article, we focus on the beliefs and instructional practices of teachers teaching students in the first three years of school ( 5 to 8 years of age). These teachers participated in professional learning focused on challenging mathematical tasks differentiated through their open-ended design and the use of enabling and extending prompts. The instructional practices are explained using the Theory of Didactical Situations. Questionnaire data from pre-intervention $(n=148)$ and post-intervention $(n=100)$ groups of teachers indicated that teachers in the postintervention group held more negative beliefs than those in the pre-intervention group about the capability of instructional approaches involving a priori grouping of students by performance levels. Interviews with ten teachers from the post-intervention group revealed and characterized the ways teachers employed open-ended tasks with enabling and extending prompts to engage all learners. Findings reveal that teachers knowing their students as individual learners accompanied by knowledge of a range of teaching practices to differentiate instruction are central to engaging all learners.
\end{abstract}

Keywords: differentiation; challenge; struggle; didactical; a-didactical; responsive teaching; growth mindset; student-centered instruction

\section{Introduction}

A major challenge facing teachers at all levels of education is the ability to address the diverse needs of individual students in the mathematics classroom [1-3]. Traditional approaches to student diversity include tracking classes or within-class groupings according to prior achievement. In both these approaches, students are usually given different tasks that vary in cognitive demand and sometimes, in content, which can exacerbate existing achievement gaps [4]. A more equitable and desirable approach currently advocated by most educational systems, involves whole-class instruction that is adaptive to individual student needs [5]. When teachers thoughtfully plan to adapt their instruction to the needs of a diverse group of learners, we refer to this as differentiated instruction [1,3]; the ultimate goal of which is to improve learning for all students. Within-class differentiated instruction might involve adaptations to content, teaching strategies, learner outcomes, or learning time [6]. Another important consideration is task design [2].

Tasks are a core element in a differentiated pedagogical approach-a task that is cognitively challenging for one student might be routine for another [7]. Holzäpfel et al. [2] suggest that mathematical tasks with high differentiation potential provide a possible strategy to help address the diverse needs of students. However, research tells us that task 
design alone, does not guarantee that all students will achieve their learning potential [8,9]. Classroom norms that respect differences among learners and encourage individual autonomy are integral to classrooms where differentiated instruction is practised and are reflective of student-centered teaching approaches $[1,3,7]$. Maintaining an optimal balance between autonomy and teacher support as students with diverse needs work on the same task is acknowledged as an aspect of quality teaching [10,11], but also as one of the most difficult aspects of teaching to implement in the classroom [3]. Studies of teaching approaches for differentiating mathematics instruction have focused on teachers of middle school [1] and high school [3], but we could not find any that have explicitly examined the instructional beliefs or practices of teachers working with students in the first three years of school. Just as rare is research reporting the practices of early years teachers who differentiate mathematics instruction through a focus on challenging tasks despite current curriculum documents, educational systems, and reports of international comparative studies espousing the benefits of such approaches $[5,12,13]$.

The current study was designed to address this gap in the research literature. Our aim was to develop a better understanding of the beliefs and reported practices of primary teachers teaching students in the first three years of school (Foundation to Grade 2). These teachers participated in professional learning focused on challenging tasks differentiated through their open-ended design and the use of enabling and extending prompts. The findings may assist other teachers to embrace challenging tasks and will have implications for instructional strategies that teachers implement to support the needs of diverse learners in their classrooms.

In the context of differentiated mathematics instruction, student-centered approaches emphasizing challenge have social, psychological, and didactical implications [7,14]. In the next sections, we discuss literature highlighting the importance of challenge and struggle for student learning of mathematics and present our perspective on tasks that have the potential to achieve an optimal level of challenge and engagement for students with diverse needs. Integral to this discussion are teachers' beliefs about how students learn mathematics and the nature of instruction that is reflective of such beliefs. Following this, we introduce our instructional approach and the research project in which this study was situated.

\section{Literature Review}

\subsection{Challenge, Struggle, and the Design of Mathematical Tasks}

In the past few decades, the construct of challenge has become an essential element of mathematics instructional approaches that promote conceptual understanding, learner autonomy and mathematical reasoning $[7,15]$. Despite growing emphasis on challenge as a focus of mathematics instruction in research literature and curriculum documents [16,17], concerns have been raised by practitioners and policymakers about whether such approaches benefit students with specialized academic needs, with some perceiving that challenging mathematics is solely for gifted students $[7,18]$. However, there is a growing body of research utilizing large sets of student achievement data that now confirms conceptually demanding instructional approaches can meet the needs of diverse groups of students $[18,19]$. In a study designed to examine whether exposure to a set of teaching practices emphasizing conceptually based and cognitively demanding mathematics would be effective for a diverse group of upper primary students $(n=10,575)$ from the United States, Blazar and Archer [18] found that "when implemented in general education classrooms ... the use of conceptually based teaching shows benefits for all students" (p. 306). Mathematical tasks and lessons that require students to use higher order thinking, reasoning and make connections among concepts, procedures, and representations, are considered necessary for conceptual understanding. There is a convergence of evidence indicating that "students are more likely to make sense of mathematics and remember what they have learned if they work on tasks that are appropriately challenging" [16] (p. 6). 
Tasks and problems are considered challenging when the answers or procedures to solve them are not immediately obvious to students and therefore provide them with opportunities for prolonged thinking, reasoning, problem solving, and risk taking [20]. Our approach to the design and implementation of challenging tasks is informed by Vygotsky's [21] zone of proximal development in that the tasks need to be optimally challenging and achievable with minimal support from teachers that does not involve telling students answers or how to solve them, and the notion of mathematical mindsets [22]. Dweck [22] categorized students' orientations to learning as reflective of a growth or fixed mindset. Students with a growth mindset approach challenging tasks with a belief that they can develop and learn through effort and persistence. Drawing upon these notions and research by Smith and Stein [23] and Sullivan and colleagues [20,24], we designed challenging tasks for the current research project with the following characteristics:

- Students did not know initially how to solve or how to proceed;

- Build on what students already know;

- Are open-ended in that there is more than one correct answer and/or more than one solution pathway;

- Take time to solve;

- Are engaging for students in that they are interested in, and see value in persisting working on them;

- $\quad$ Are simply posed;

- Focus on important aspects of mathematics; and

- Foster connections within mathematics and across domains.

Especially relevant to the current study, is the open-ended nature of the tasks designed. Open-ended tasks usually have multiple correct solutions and/or solution pathways, generally providing the opportunity for all students to access tasks from a "low-floor" starting point and everyone to eventually struggle due to their "high-ceiling" potential [25]. Consider an example task: "In a photo of a farmyard, you can see 12 legs. Draw what the animals might be." This task is open-ended because there are multiple solutions and multiple ways in which students can derive their solutions. It is intended that the same task be provided to all students in the class with the expectation that some students may only provide one solution and that more academically capable students will provide multiple solutions.

Integral to this work on challenging tasks is student struggle and the strategies teachers employ to differentiate learning. Struggle involves students expending effort while experiencing some level of confusion while attempting to solve challenging tasks. Hiebert and Grouws [26] suggest that struggle is particularly important for students to develop conceptual understanding. They claim that if students struggle in order to make sense of mathematics, they are more likely to remember the mathematics. At the same time, students are more likely to develop a disposition for persistence and an underlying growth mindset. Struggle, therefore, is arguably an essential aspect of conceptually based teaching approaches. However, keeping a task within an individual student's zone of proximal development (ZPD) is a critical aspect of teaching with challenging tasks. If a task is too challenging or too easy, students will become disengaged. Sullivan, Mousley, and Jorgenson [25] outlined two major strategies teachers can use to differentiate the learning experience for individual students while they are working on challenging tasks with the effect of keeping the level of challenge within each students ZPD. Enabling prompts are strategies to engage students who are not progressing on the original task. Such strategies might involve a reduction in the number of steps, less complex numbers, or a variation in the representation involved in the task. For the example task provided above, a suitable enabling prompt might be for a student to only use six animal legs. Importantly, these prompts do not tell students how to proceed and are designed to re-engage them in the original task. On the other hand, extending prompts are used to engage students who find the original task easy and are intended to elicit abstraction and generalisation of solutions. A suitable extending prompt for the farmyard problem is for students to: "Find how many 
different combinations of animals are possible?" Enabling and extending prompts used to differentiate task difficulty are offered only after students have engaged with the original task for some time.

In short, there is acknowledgement from various researchers and curriculum documents that challenge and struggle in mathematics are important elements in instructional approaches emphasizing conceptual learning. Further, it is possible to differentiate learning utilizing such approaches through carefully designed tasks and explicit instructional strategies such as enabling and extending prompts.

\subsection{Teacher Beliefs}

Critical aspects to the implementation of any instructional approach in the classroom are teachers' beliefs about the nature of mathematics and how students effectively learn it $[27,28]$. While there is an extensive body of literature documenting teachers' beliefs about student-centered, conceptually based or "reform" instructional approaches [29,30], research specifically exploring teachers' beliefs about challenge and student struggle, is only just emerging [31,32]. According to Applebaum and Leikin [7], teachers' conceptions of mathematical challenge are "situated in their practice and rooted in their knowledge and beliefs about the nature and structure of mathematical tasks" (p. 4). Therefore, if we wish to improve teachers' practices for differentiating mathematics involving cognitively demanding tasks, we need to better understand their beliefs about mathematical challenge and the teaching strategies considered effective for diverse groups of students.

A growth mindset was previously mentioned as important to develop in students because of the links between a growth mindset and their propensity to persist solving challenging problems [22]. Equally important is a teacher's mindset. Teachers who possess a growth mindset are likely to believe that all students have the potential to learn challenging mathematics and are more willing to embrace student struggle when working on challenging mathematics [31] than teachers with a fixed mindset. This implies that teachers with a growth mindset are also likely to be more adaptive in their teaching strategies when responding to the needs of diverse learners.

Teachers' willingness to adapt instruction to students' needs is related to their ideas about responsiveness in teaching [1,33]. According to Richards and Robertson [33], responsive teachers believe students' ideas are central to instruction and it is a teacher's role to build connections between these initial ideas and more sophisticated ways of thinking. Such beliefs are associated with both student-centered and differentiated instructional approaches "because viewing students' ideas as central and pursuing them allows a teacher to adjust instruction to differences in those ideas" [1] (p. 3). Adjusting instruction based on student ideas requires teachers to not only know their students well, but also to know how and when to respond in appropriate ways. This leads us to a discussion of the instructional approach and project in which the current study was embedded.

\subsection{EMC ${ }^{3}$ Project Instructional Approach}

Our instructional approach was developed as part of the Exploring Mathematics Sequences of Connected, Cumulative, and Challenging tasks project $\left(\mathrm{EMC}^{3}\right)$. For three years we have been working with successive groups of primary school teachers who teach students in their first three years of school (Foundation to Grade 2) across two Australian school systems in the adoption of a student-centered, structured inquiry approach [32]. Each new cohort of teachers is introduced to the $\mathrm{EMC}^{3}$ approach during a full day of professional learning with the research team at the start of each year. They are also provided with a resource kit comprising sequences of challenging tasks and suggestions for their implementation. Support for enactment of the approach is provided to teachers through school visits from members of the research team. Central to our teaching approach, and particularly relevant to the current study, is a belief that all students learn more effectively when engaged in optimally challenging tasks. To this end, the challenging tasks used in 
the project are differentiated for diverse groups of students by their open-ended design and the use of enabling and extending prompts.

The $\mathrm{EMC}^{3}$ approach emerged from an evidence base of prior research from a wide range of researchers [23,34-38], theorists [22,39-42], and our own involvement in research projects focused on challenging mathematics $[24,43,44]$. Although not conceived with prior knowledge of the Theory of Didactical Situations (TDS) as proposed by Brousseau [45], we find it useful to reflect upon the $\mathrm{EMC}^{3}$ approach in the light of such theory. As a systematic framework of instruction specific to mathematics, TDS enables us to articulate purposes of each phase of the $\mathrm{EMC}^{3}$ lesson structure and clarify specific instructional elements characterizing each phase within lessons and across sequences of lessons. While a detailed account of TDS is provided elsewhere [45,46], here we focus on the main constructs of TDS necessary for gaining a deeper understanding of our own approach.

Although the $\mathrm{EMC}^{3}$ project's ultimate goal is the enhancement of students' conceptual understanding of mathematics, like TDS, our approach targets particular mathematical knowledge through the creation of a sequence of situations in the classroom in which student learning of that knowledge is enabled. Our instructional model draws heavily on Smith and Stein [23], which, as is the case in TDS, focuses on orchestrating classroom discussions. The first element of the $\mathrm{EMC}^{3}$ instructional model is "Anticipate", which is enacted prior to the lesson and requires teachers to:

- Identify the specific mathematical knowledge to be targeted, and articulating the learning goals and strategies for prompting students to learn the targeted knowledge;

- Choose tasks based on the learning goals, the curriculum, and prior knowledge of students;

- Select resources, materials, and ways for students to represent their thinking;

- Anticipate students' solutions and strategies; and

- Plan enabling and extending prompts.

TDS is structured around the notions of $a$-didactical and didactical situations. Brousseau [45] explains that during a-didactical situations, the teacher refrains from any form of explicit teaching. The first part of a lesson is didactical, involving a process of devolution where "students accept to take the mathematical responsibility of solving a given problem" [46] (p. 51). Devolution connects with the EMC "Launch", for which our advice for teachers is to:

- Lead a preliminary activity related to the content of the lesson or a discussion to familiarize students with the lesson context;

- Pose the main task, with students reading the question for themselves where possible, without instructing students on solution path or method; and

- Invite questions to clarify language, materials, and representations.

We see key aspects of transferring responsibility are not only to communicate to students (and their teachers) that they will have to do the thinking, but that they can also choose the type and format of the solution.

The next phases of TDS are action and formulation. We describe this as the "Explore" phase where teachers are advised to:

- Allow individual think time after which students might work collaboratively;

- Interact with students, observe and monitor how they are responding;

- Offer enabling prompts to students who are stuck and extending prompts to students who have finished;

- Select student work samples for subsequent sharing and discussion; and

- Intervene after about $10 \mathrm{~min}$ if many students are not progressing, encourage sharing of partial solutions and/or discuss misconceptions that have arisen.

Action refers to students creating solutions individually or collaboratively and Formulation implies that the teacher prompts students to go beyond their individual solutions to seek and describe patterns and form generalizations. 
The next phase of TDS is validation, which is analogous to what we describe as "Summarize" and suggest to teachers that they:

- Sequence the selected work samples;

- Support students in articulating solutions and strategies by revoicing when necessary; and

- $\quad$ Pose questions to stimulate student thinking, connect mathematical ideas and build understandings.

The teacher, at this phase, leads a discussion of student solutions, engaging other students in thinking about these solutions, and builds connections between the solutions and the discussion that is prompted.

While we describe Summarize/Review as occurring contemporaneously, it involves a potential shift in the locus of control from students to the teacher. This move from a-didactical to didactical learning situations is termed Institutionalization in TDS. We describe this as "Review" in which we encourage teachers to synthesize, emphasize and record key mathematics points building on student contributions.

The process from Anticipate to Review happens twice for each learning experience with the task for the second cycle based on Variation Theory [39]. The variant might be the context with the concepts being invariant, or the sophistication of concept might be variant with the context being invariant. For example, the "reLaunch" might involve the teacher posing a further task that is "a bit the same and a bit different" from the original to consolidate and extend the learning from the first task. The "reExplore" phase uses the same approach as for the exploration of the initial task, with responses from students who have applied new or more sophisticated strategies from the earlier discussion specifically affirmed. The "reSummarize/Review" phase also uses the same approach as for the review of the initial task, emphasizing overall learning and anticipating how the new knowledge might be used in the future.

In the context of the above background research literature and the broader $\mathrm{EMC}^{3}$ project, we now focus on the current study, which sought to explore the beliefs and reported practices of teachers participating in our project. Our analysis was guided by the following research questions:

- What beliefs do Foundation to Grade 2 teachers hold concerning an instructional approach that emphasizes challenge and student-centered learning?

- What instructional practices do Foundation to Grade 2 teachers report using to engage all students in the learning of challenging mathematics, and how are they enacted?

\section{Materials and Methods}

Participants in this study were drawn from two groups of Foundation to Grade 2 (F-2) generalist Australian primary teachers who participated in the $\mathrm{EMC}^{3}$ professional learning program. Following ethics approval from the Monash University Human Research Ethics Committee (SCERH number 10791), data were collected from teachers to explore their beliefs and instructional approaches for differentiating instruction via questionnaires and semi-structured interviews. Note that while our main interest was in the post-intervention group of teachers, there was no pre-intervention data available in terms of their beliefs about approaches to differentiation. We therefore drew upon pre-intervention data from a subsequent group of teachers undertaking the same program as a comparison group.

As part of the pre-intervention $(n=148)$ and post-intervention $(n=100)$ questionnaires, teachers were asked a range of background questions, including their prior involvement in professional learning regarding challenging tasks. They were also asked to indicate the degree to which they considered each of eight different approaches useful for teaching mathematics by responding to the prompt: "The following teaching approaches are useful for catering to students of different performance levels in the mathematics classroom". The eight different teaching approaches included: 
1. Presenting the whole class with the same core problem-solving task, differentiated through the task having a "low floor, high ceiling" (Problem solving-Low floor, high ceiling).

2. Presenting the whole class with the same core problem-solving task, differentiated through students accessing enabling and extending prompts (Problem solving_-prompts).

3. Within class performance grouping, where similar-performing groups rotate through workstations undertaking activities matched to their performance level (Grouped in-class rotations).

4. Between class performance grouping ("fluid groupings"), where similar-performing students are grouped together across classes and undertake activities that match their performance level (Fluid groupings).

5. Playing the same mathematical game with the whole class in similar-performing groups, with the game differentiated through groups using resources matched to their performance level (Grouped game).

6. Playing the same mathematical game with the whole class in mixed-performing groups, with the game "naturally" differentiated through students using strategies of choice (Mixed game).

7. Allowing students to work through worksheets at different levels of challenge, depending on their performance level (Grouped Worksheets).

8. Allowing students to work through on-line activities/Apps at different levels of challenge, depending on their performance level (Grouped Online).

Participants recorded their response on a 7-point scale, presented with two anchors (1-not at all useful; 7-extremely useful). Mean scores and the percentage of teachers' responses were calculated for each approach to teaching. A series of independent samples t-tests was undertaken to compare mean scores between the pre- and post-intervention groups, using a Bonferroni adjusted significance value to correct for compounding type 1 error.

On a convenience basis, ten teachers from the post-intervention group were invited to participate in an individual semi-structured interview. The purpose of the interview was to probe their experiences teaching mathematics using the approach advocated in $\mathrm{EMC}^{3}$. Although the interview questions did not specifically focus on the instructional aspects that teachers considered worked best for engaging all students in learning mathematics, we anticipated relevant responses given the $\mathrm{EMC}^{3}$ approach. All 10 teachers consented to participate in the semi-structured interviews. Seven interviewees were established teachers, having been teaching between 6 and 10 years, and three were novices (i.e., in their first two years of teaching). For a summary profile of interviewees, see Table 1.

Table 1. Interviewees' years of experience and current grade level teaching.

\begin{tabular}{ccc}
\hline Teacher & $\begin{array}{c}\text { Years of } \\
\text { Experience }\end{array}$ & $\begin{array}{c}\text { Current Grade } \\
\text { Level Teaching }\end{array}$ \\
\hline Larissa 1 & 9 & Grade 1 \\
Jen & 6 & Grade 1 \\
Pene & 6 & Grade $1 / 2$ \\
Steph & 7 & Grade $1 / 2$ \\
Julie & 9 & Foundation \\
Dane & 11 & Grade 2 \\
Sarah & 2 & Grade $1 / 2$ \\
Fiona & 1 & Foundation \\
Jane & 2 & Grade $1 / 2$ \\
Ellen & 7 & Grade $1 / 2$ \\
\hline
\end{tabular}

${ }^{1}$ All names are pseudonyms.

Interviews lasted for approximately $30 \mathrm{~min}$ each, were conducted by a member of the research team and audio-recorded for later transcription. Transcripts were analyzed using an adaptation of Braun and Clark's [47] process for thematic analysis. First, familiarity 
with the data was obtained from multiple readings of each transcript. Data were then coded using both a priori and data-driven codes to account for features underpinning the approach advocated during the program and to capture unexpected codes as they emerged. For instance, we approached analysis knowing that we were looking for comments relating to the overarching domains of teacher beliefs and instructional strategies. We had also anticipated from survey results and the focus of our PL approach that whole class instruction utilizing open-ended tasks designed with a low floor/high ceiling structure, and the use of enabling or extending prompts would be mentioned by teachers. However, we did not know if teachers perceived these aspects of pedagogy helpful or, indeed, if and how they used them in the classroom. The third step in analysis involved identification of initial patterns or themes in the coding. This step allowed us to characterize salient features of data considered most relevant to answering the research questions or that corresponded to a theme identified in the literature as being relevant to teaching approaches involving differentiated instruction. Reviewing and naming themes and codes was then undertaken to finalize the analysis.

The final set of four themes, comprising codes and sample quotations are presented in Table 2. Following each quotation is the name of the teacher and the transcript page number from which the quotation was extracted.

Table 2. Major themes, codes. and sample quotes.

\begin{tabular}{|c|c|c|c|}
\hline Domain & Theme & Code & Sample Quotes \\
\hline \multirow{4}{*}{ Beliefs } & \multirow{2}{*}{$\begin{array}{l}\text { * Growth mindset: } \\
\text { All students can achieve in } \\
\text { mathematics }\end{array}$} & * Struggle & $\begin{array}{l}\text { I think that struggle is important, because if you're not really } \\
\text { struggling at some point, you're not really learning. (Pene 5) }\end{array}$ \\
\hline & & * Challenge & $\begin{array}{l}\text { It was a challenge for them. But at the end of it, they did get it, } \\
\text { they did achieve... But it proved that the approach does work } \\
\text { for all kids, it's just different in how quickly they're going to } \\
\text { grasp it. (Jen 2) }\end{array}$ \\
\hline & \multirow{2}{*}{$\begin{array}{l}\text { Responsive teaching: } \\
\text { Students' ideas are central, } \\
\text { teachers adapt instruction to } \\
\text { students and contexts; }\end{array}$} & $\begin{array}{l}\text { * Knowing students well } \\
\text { and knowing when to } \\
\text { intervene }\end{array}$ & $\begin{array}{l}\text { Knowing that child, whether they can deal with it ... the } \\
\text { struggle time, I think it's completely different for each child. } \\
\text { Some of them, I let them go for } 10 \text { min, and know that they'll } \\
\text { get it ... But some, you've got to step in. (Pene 5) }\end{array}$ \\
\hline & & $\begin{array}{l}\text { Student-centered } \\
\text { community of learners }\end{array}$ & $\begin{array}{c}\text { You're sitting back and letting them unpack it rather than you } \\
\text { saying it...the kids are teaching the kids and I find that } \\
\text { sometimes they listen better. (Larissa 2) }\end{array}$ \\
\hline \multirow{7}{*}{$\begin{array}{l}\text { Instructional } \\
\text { strategies }\end{array}$} & \multirow{4}{*}{$\begin{array}{l}\text { *A-Didactical: } \\
\text { Established norms encourage } \\
\text { student autonomy }\end{array}$} & $\begin{array}{l}\text { Student choice of materials, } \\
\text { strategies and methods }\end{array}$ & $\begin{array}{c}\text {... them (students) using their own strategies and finding a } \\
\text { way to build on that strategy that they're using. Just letting } \\
\text { them use their strategies of choice. (Dane 7) }\end{array}$ \\
\hline & & $\begin{array}{l}\text { * Tasks are open-ended, low } \\
\text { floor / high ceiling }\end{array}$ & $\begin{array}{l}\text { The tasks give everyone that opportunity to start at a point, } \\
\text { and then go from there. (Steph 3) }\end{array}$ \\
\hline & & Whole class instruction & $\begin{array}{l}\text { I gave the task to all of the kids, and I would say that it was } \\
\text { quite difficult. (Pene 1) }\end{array}$ \\
\hline & & $\begin{array}{l}\text { Allow for struggle and } \\
\text { thinking alone time }\end{array}$ & $\begin{array}{l}\text {... they have their own thinking time first and then they start } \\
\text { sharing their ideas. (Julie 10) }\end{array}$ \\
\hline & \multirow{3}{*}{$\begin{array}{l}\text { * Didactical: } \\
\text { A variety of specific and } \\
\text { intentional strategies to } \\
\text { engage all students }\end{array}$} & $\begin{array}{l}\text { Contextualize the learning } \\
\text { to help students connect } \\
\text { and make sense of } \\
\text { mathematics }\end{array}$ & $\begin{array}{c}\text { I always break it up into a personal story. Because they are very } \\
\text { limited in their vocabulary ... just exploring the vocabulary } \\
\text { with them is important. ... We try and look for a picture book } \\
\text { just to get that connection with the problem. (Fiona 3) }\end{array}$ \\
\hline & & $\begin{array}{l}\text { Knowing how to support } \\
\text { students via specific } \\
\text { prompts }\end{array}$ & $\begin{array}{l}\text { They need to touch tangible shapes. They need to go out and } \\
\text { explore and see what they can find. The language ... of maths } \\
\text { is really important. (Ellen } 6 \text { ) }\end{array}$ \\
\hline & & Consolidation of learning & $\begin{array}{l}\text { Usually, it is a sequence ... The lessons build on top of each } \\
\text { other so that the understanding just goes deeper and deeper. } \\
\text { (Ellen 6) }\end{array}$ \\
\hline
\end{tabular}

* a priori themes and codes. 


\section{Results}

\subsection{Questionnare}

Questionnaire data for the pre- and post-intervention groups of teachers are presented in Tables 3 and 4, respectively.

Table 3. Pre-intervention $(n=148)$ teacher responses.

\begin{tabular}{ccccc}
\hline Approach & Mean Score & Percentage Positive (5, 6, 7) & $\begin{array}{c}\text { Percentage “Extremely } \\
\text { Useful” (7) }\end{array}$ & $\begin{array}{c}\text { Percentage “Not at All } \\
\text { Useful” (1) }\end{array}$ \\
\hline Problem solving_Low & 5.36 & $71.6 \%$ & $25.7 \%$ & $0.7 \%$ \\
Floor, High Ceiling & 6.11 & $92.6 \%$ & $43.2 \%$ & $0.0 \%$ \\
Problem solving_Prompts & 3.95 & $40.5 \%$ & $5.4 \%$ & $5.4 \%$ \\
Grouped rotations & 4.34 & $50.0 \%$ & $6.8 \%$ & $4.1 \%$ \\
Fluid groupings & 5.03 & $65.5 \%$ & $15.5 \%$ & $1.4 \%$ \\
Grouped Game & 5.29 & $75.7 \%$ & $17.6 \%$ & $0.7 \%$ \\
Mixed Game & 2.61 & $15.5 \%$ & $2.7 \%$ & $29.1 \%$ \\
Grouped worksheets & 3.62 & $29.4 \%$ & $6.1 \%$ & $10.1 \%$ \\
Grouped Online & & & \\
\hline
\end{tabular}

Table 4. Post-intervention $(n=100)$ teacher responses.

\begin{tabular}{ccccc}
\hline Approach & Mean Score & Percentage Positive (5, 6, 7) & $\begin{array}{c}\text { Percentage “Extremely } \\
\text { Useful” (7) }\end{array}$ & $\begin{array}{c}\text { Percentage “Not at All } \\
\text { Useful” (1) }\end{array}$ \\
\hline Problem solving_Low & 5.65 & $83.0 \%$ & $33.0 \%$ & $1.0 \%$ \\
Floor, High Ceiling & 6.12 & $90.0 \%$ & $50.0 \%$ & $0.0 \%$ \\
Problem solving_Prompts & 3.27 & $28.0 \%$ & $1.0 \%$ & $21.0 \%$ \\
Grouped rotations * & 3.41 & $35.0 \%$ & $3.0 \%$ & $21.0 \%$ \\
Fluid groupings & 4.36 & $46.0 \%$ & $11.0 \%$ & $3.0 \%$ \\
Grouped Game & 5.55 & $83.0 \%$ & $23.0 \%$ & $1.0 \%$ \\
Mixed Game & 2.65 & $24.0 \%$ & $4.0 \%$ & $44.0 \%$ \\
Grouped worksheets & 3.11 & $27.0 \%$ & $4.0 \%$ & $21.0 \%$ \\
Grouped Online & & & \\
\hline
\end{tabular}

* Indicates a statistically significant decline in mean score between the pre- and post-intervention group, as indicated by an independent samples t-test using a Bonferroni corrected significance value of $p=0.05 / 8$.

Comparing the two data sets, it is clear that teachers in both samples reported very positive views about problem solving tasks differentiated through the use of enabling and extending prompts. This pedagogical approach is clearly believed to be effective in supporting students of different performance levels both for the group who had not yet participated in $\mathrm{EMC}^{3}$ (pre-intervention group), and for the group that had participated in the $\mathrm{EMC}^{3}$ professional learning (post-intervention group). This similarity likely reflects the fact that teachers in the pre-intervention group already had substantial exposure to teaching with challenging tasks and found this approach valuable. In fact, only $13 \%$ of these teachers reported having had no prior professional learning exposure to challenging tasks. Other teachers had exposure to challenging tasks primarily through school-based professional learning, mathematics teacher education conferences, attending external professional learning workshops and/ or through their pre-service teacher education experience.

There were some notable differences between the groups. In particular, teachers in the post-intervention group were notably more negative about the capacity of pedagogical approaches that involved a priori grouping of students by performance levels. Specifically, a series of independent samples t-tests indicated that, on average, teachers in the postintervention group were significantly less positive about the capacity of fluid groupings ( $p=0.0001)$, grouped rotations $(p=0.0031)$, and grouped games $(p=0.0023)$ to support differentiated instruction compared with teachers in the pre-intervention group; although the apparent difference in grouped online activities was not significant after the Bonferroni correction was applied $(p=0.044)$. Similarly, there were no differences in endorsement 
of grouped worksheets $(p=0.8672)$, which was consistently viewed as the instructional approach least supportive of differentiation.

Descriptive data helps to further emphasize the differences in the views of the two groups. For example, only around 1 in 20 teachers in the pre-intervention group believed that fluid groupings or grouped rotations were "not at all" useful at catering to different performance levels, compared with 1 in 5 teachers in the post-intervention group. Similarly, albeit somewhat less dramatic, differences were noted for the three other pedagogical approaches that involved a priori performance groupings: Grouped worksheets, Grouped online and Grouped games. By contrast, although there were no statistically significant differences in mean scores, descriptive data indicates that the post-intervention group was somewhat more positive about pedagogical approaches that did not involve a priori performance grouping in terms of the percentage of teachers believing such approaches were "extremely useful" for catering to students of different performance levels.

Table 4 reveals that three teaching approaches were viewed by the majority of teachers from the post-intervention group as being particularly useful for catering to students of different performance levels in the mathematics classroom:

- Presenting the whole class with the same core problem-solving task, differentiated through students accessing enabling and extending prompts;

- Presenting the whole class with the same core problem-solving task, differentiated through the task having a "low floor, high ceiling"; and

- Playing the same mathematical game with the whole class in mixed-performing groups, with the game "naturally" differentiated through students using strategies of choice.

These three approaches have important similarities. Perhaps most importantly, they are the only three approaches that do not involve some form of a priori grouping of students according to perceived mathematical performance, whether such groupings take place within the classroom (grouped game; grouped rotations; grouped online; grouped worksheets) or between classrooms (fluid groupings).

It is particularly encouraging that as many as $90 \%$ of teachers believed that differentiating problem solving tasks through students accessing enabling and extending prompts is a useful means of catering to different performance levels, with half of the teachers describing this approach as extremely useful. Such tasks formed the core of the learning sequences that teachers accessed as part of $\mathrm{EMC}^{3}$, and the implication is that this approach was effective at allowing students of all levels to access the tasks.

\subsection{Interviews}

Of the four major themes identified during analysis of the interviews, two were relevant to the domain of teacher beliefs-growth mindset and responsive teaching. The other two themes related to the domain of instructional strategies-a-didactical and didactical. Although each theme is discussed separately in the following sections, it is important to note that many participants' responses were coded to multiple themes. One reason for this was that teachers often stated a belief and then directly followed with specific examples from their practice to elaborate on their point.

\subsubsection{Growth Mindset: All Students Can Achieve in Mathematics}

Each of the ten teachers expressed a strong belief that all students can achieve in mathematics but that the pace at which students learn, the level to which they might achieve, and the level of support they require to achieve, is "completely different for each child" (Pene 5). However, not all teachers felt this way at the start of the project. Jen, Larissa, and Sarah commented that when they first started to implement the $\mathrm{EMC}^{3}$ approach, they were worried that it would not cater for very young students or their less capable learners. Jen found that after only a few lessons, both she and "the kids were adapting ... to that style of learning" and that even her at-risk students "did get it, they did achieve their 
outcome ... it proved that the approach does work for all kids, it's just different in how quickly they're going to grasp it" (Jen 2).

Teachers recognized the significance of both struggle and challenge when learning mathematics, and how both these aspects positively contributed to the development of a growth mindset. Nearly all teachers described how they believed it was important to cultivate a growth mindset in their students by emphasizing persistence on challenging tasks, the importance of struggle when learning and how mistakes can provide an opportunity for further learning:

"I think about the engagement and the struggle, I think a lot of it is to do with their mindset-so much of it. We've done heaps of work on what's a mathematician. A mathematician never gives up, tries, listens to other people's strategies" (Jen 4)

"We had this whole discussion about how you got to be in the challenge zone and that it's okay to make a mistake. Then once a couple of kids were starting to get on the right track, the others thought, "if they can do it, then I should be able to do it!" There was that mentality" (Larissa 2)

"It would be bad for them if you pulled the plug because then you're saying, "you're not going to get it". I explained to them that it's okay to not get this in the one session ... I tried to get them to realize that they are actually learning something ... Even if they are struggling" (Dane 8)

Importantly, teachers recognized the value of challenging tasks and their potential for encouraging children's higher order thinking. Pene and Ellen explicitly mentioned how much they liked "the idea of challenging tasks". They felt that challenge contributed to the development of a positive mathematical disposition because "thinking is so important and if we want them to be thinkers and problem-solvers, then we actually have to provide them with tasks that allow them to do that" (Ellen 8). However, as revealed in our consideration of the next theme, the approach to teaching required to nurture such disposition was something that some teachers initially struggled to embrace.

\subsubsection{Responsive Teaching}

Accompanying teachers' belief in a growth mindset was their belief in the importance of knowing their students well so that they were able to adapt their instruction to cater for a diversity of students. This belief included a view of students' ideas and strategies as being central to the learning process and their own role as "a facilitator of that learning" (Julie 10). Teacher statements explicitly reflecting this belief and view of student learning were categorized under the theme of responsive teaching. These statements corresponded to Richards and Robertson's [33] description of responsive teachers as those who view students' ideas as central, allowing them to adapt their instruction to different students and contexts. This theme also seemed to permeate teachers' comments coded to themes relating to the instructional strategy domain. This is understandable, given that this belief actually underpins the proclivity of teachers to differentiate instruction while maintaining a balance between challenge and struggle. Namely, if a teacher does not know their student well, they are not able to appropriately respond. This belief was clearly articulated by Julie when she stated that, " ... it's about knowing what the students know and knowing how to target them within that scenario" (Julie 9).

Other teachers emphasized the importance of noticing individual student responses to "gauge if they're confused" (Sarah 7). Accompanying these comments, teachers acknowledged that it was critical for them to also have the capacity to make professional judgements about how and when to intervene and support students:

"I think it comes down to personal-you as a teacher knowing the child. Some children can sit there for quite a long time, and struggle, and you know they're actually sitting there thinking and they're okay with being in the struggle zone. Then you've got the other kids that-it will just knock them down if they continue, 
if you let them go for too long. So, I think that struggle is important but it's really teacher judgement" (Pene 5)

All ten teachers affirmed their belief in placing students' thinking and strategies central to instruction. In doing so, teachers' comments reflected a student-centered approach whereby they learnt to let the students take "control of their learning" (Sarah 3) and "build on each other's thinking" (Jen 10). However, this letting go of control was a challenge for most teachers. Larissa, Jen, Julie, Steph, Sarah, and Ellen explained how the change in approach took time for them to "trust the process" before they could "let go of control a bit" (Jen 2):

"In the beginning, it was quite a struggle even for me to step back a bit and not be so explicit in my teaching. And as we continued to do the challenging tasks it became easier for the students to understand what was expected of them and they learned that that's not what every lesson is going to look like and that they are not going to have a teacher or someone else sweeping in and guiding them" (Ellen 3)

"It was very hard to sit there and bite your tongue because ... I just wanted to help them. But you had to stay back ... This way of doing it you see far better results. You're sitting back and letting them unpack it rather than you saying it. But the kids are teaching the kids and I find that sometimes they listen better" (Larissa 2)

The process of learning to transfer control to the students occurred gradually and intentionally for most teachers as they reflected on their teaching and student responses. Sarah commented that after each lesson, "I reflected on my ability to deliver it", and occasionally, she repeated the same lesson but "changed the way that I spoke my instructions ... and then they [students] went off and had a go" (Sarah 3). Both Jen and Larissa referred to this process as being "a bit stressful ... because you can't really plan for where it's going to go" but at the same time "more exciting" (Jen 4) to see "the amount of information you get from them ... this is what it should be like" as students developed confidence and autonomy in their learning of mathematics.

The teachers described how they would place themselves on the "same level" as their students (Sarah 7) to encourage a sense that they were all part of a community of learners:

"I sat there, and I did a bit of work with them to show them that I was doing it alongside them.... I like the fact that they're in control of their learning so far that I'm not just talking at them" (Sarah 3)

A belief in responsive teaching had implications for the specific instructional moves teachers implemented to suit the needs of diverse learners. Hence, the next two themes relate to the major domain of instructional strategies and incorporate specific moves teachers reported using during a-didactical and didactical phases of their mathematics lessons. Importantly, teachers intentionally used different instructional moves in each of these lesson phases.

\subsubsection{A-Didactical}

The teachers referred to a range of strategies and associated instructional elements that contributed to a phase in their lessons where students were encouraged to take responsibility for their mathematical learning, and the teacher refrained from intervening. Aspects of teachers' practices that were coded to this theme included their allowance for struggle and independent thinking time; tasks that were differentiated by their open-ended design; their allowance for student choice of materials, strategies, and methods; and whole class instruction. Together, these strategies and associated instructional elements reinforced routines and norms of the classroom that emphasized the importance of reasoning, struggle, problem solving, and learner autonomy.

All teachers acknowledged the importance of allowing students "independent thinking time" when students would be encouraged to "sit and mull over a problem for a 
while" (Julie 11) prior to collaborating "with their partner" (Pene 5) or "sharing their ideas" (Julie 10) with the whole class. Teachers often referred to this period of time as when their students were in "the learning pit" (Ellen 5). Some teachers, such as Steph, encouraged the students to stop her from interrupting their exploration time because she felt that this reinforced how important their independent thinking time was:

"I've been really strict on myself so that I definitely put the timer on, and I say to the kids, "If you see me turn it off, say, 'No, we need this 15-min to play with numbers'" (Steph 5)

In this case, Steph's strategy worked to actively prevent her from teaching. However, she also emphasized the importance of clarifying the task to students before they "independently go off, problem-shoot, like, and troubleshoot" for themselves (Steph 6). This clarification generally involved "reading the task" together because the majority of Steph's students were from non-English speaking backgrounds and she felt it was imperative that she knew they understood the task prior to her "stepping back".

A characteristic common to this group of teachers' instructional practices throughout every phase of their lessons, but particularly mentioned in reference to the independent thinking time, was their encouragement of student choice. Dane, Pene, Jane and Sarah explained how they always provided a "wide variety of materials" and allowed the students "to choose how they want to solve the problem" (Sarah 6). Monitoring student choice of materials and strategies provided important assessment information about the students to teachers. It also allowed teachers to build on students' existing strategies:

" ... them (students) using their own strategies and finding a way to build on that strategy that they're using. Just letting them use their strategies of choice" (Dane 7)

An aspect of the project that teachers acknowledged as imperative to the independent exploration phase of their lessons was the manner in which the tasks were designed. In particular, the open-ended nature of problems was considered to be "more engaging" (Jen 6) for students with diverse learning needs. The low floor/high ceiling design enabled "everyone that opportunity to like start at a point, and then go from there" (Steph 3), allowing even the at-risk students to "learn from the same task ... all can access it" (Julie 4).

Once students became familiar with the open-ended nature of the tasks and the expectation of multiple answers or different solution strategies, teachers described how their students also became more comfortable to independently solve problems:

"The kids actually know when there is not just one answer. Especially when it says, "how many possibilities can you find", then they're there trying to strive to find the most possible answers ... it makes them apply the same concept but to find different answers" (Larissa 5)

The open-ended nature of the tasks also had implications for how teachers structured their class for instruction. Julie and Jen explicitly referred to open-ended tasks as a reason why they shifted from "small-group" to predominantly "whole-class" (Jen 4) instruction for mathematics. Teachers commented that whole class instruction was particularly empowering for their less capable students:

"They were proud of themselves, because they were doing the work that the other kids were doing .... and they were the ones at the end when we were reflecting that could articulate what patterns they saw, and where the differences were, and why they were different ... but they got it. And they could access the task" (Pene 1)

The final theme to be considered relates to the didactical interventions of teachers via intentional and specific instructional moves. 


\subsubsection{Didactical}

Unlike the a-didactical phase of their lessons whereby students took responsibility for problem solving, there were also didactical situations when intervention by teachers was considered necessary. Such situations included the need to (re)engage learners, facilitate whole class discussions, and help students build connections between their initial ideas and sophisticated mathematical concepts or to prior learning. Aspects of teachers' practices that were coded to this theme involved a range of strategies to contextualize learning, specific enabling, and extending prompts to support the diverse needs of students, and strategies to consolidate their learning.

Teachers described situations in which they felt it was important to explicitly contextualize the learning during lessons to help the students make sense of the mathematics. The majority of these situations usually occurred when teachers were in the process of launching a task and prior to independent exploration time. Fiona explained that she contextualized lessons to help engage students with a particular task or a representation so that "they can make that connection" (Fiona 3) to the mathematics for themselves:

"I always break it up into a personal story. Because they are very limited in their vocabulary ... Just exploring the vocabulary with them is important. We try and look for a picture book just to get that connection with the problem.... Just contextualizing it" (Fiona 3)

Other teachers sought to contextualize new topics by making connections with previous tasks or a previous sequence of learning. For instance, when working on a geometry sequence, Julie commented that she would "make connections" to measurement tasks already completed and "start developing the big ideas around those kinds of topics" (Julie 9). Similarly, Jen related tasks to "something that they're interested in" or considered to be "fun" because she found that was when her students were "more engaged" (Jen 5).

As reported in earlier themes when discussing beliefs, this group of teachers acknowledged the importance of challenge, struggle and of knowing their students well so that they could not only anticipate their needs but also respond appropriately "in the moment". An implication of that belief was that these teachers also needed to know how to support their students and when it was suitable for them to provide that support or to offer extension. The most frequently cited strategies teachers described to achieve that balance between struggle and challenge was their use of enabling and extending prompts that were delivered via whole class discussions, clarification of mathematical language, manipulatives, questioning and "spotlighting" of student work.

The summarize phase in lessons, which usually occurred immediately after students had been working independently, was a period when teachers explicitly tried to engage all students in deep thinking and learning of mathematical concepts. Teachers described using whole class discussions involving the spotlighting of specific students' work where they intentionally "made connections" between children's ideas through planned questioning that encouraged them to "build on each other's thinking" (Julie 10):

"The idea of doing spotlighting (sharing work samples) and everyone stops and then the students go, "oh, you know, I'm trying this" and the kids show their work .... And the others are "that sounds like a great idea", and then they go back and then they try it that way. And then later on I'll notice somebody else and they will be a spotlight for a different strategy" (Ellen 3)

Jane, Sarah, and Fiona described their use of manipulatives as an enabling prompt for "those ones that struggle, I just find ... it really helps them make more sense of it" (Fiona 2). Similarly, Dane used "a lot [of] physical materials particularly if they are struggling" (Dane 8). Importantly, teachers recognized that not all their students needed the same level of support, with Sarah explaining that some of her students "can do it mentally, but some of my students still need the concrete materials to make that connection" (Sarah 6). Teachers emphasized that they often needed to make a professional judgement in terms of when 
and how to support students. Some teachers, like Ellen, gave her Year 1 and 2 students the choice of whether they accessed the enabling prompts she made available:

"For our really at risk kids, they like the idea that they're doing everything the same as everyone else and that if they needed to, they could go and get an enabling prompt. It was just depending on the task" (Ellen 3)

Teachers also described specific strategies they used to help consolidate students learning of mathematics concepts. Consolidation strategies mentioned by teachers during the interviews included the repetition of important information about mathematical concepts and of tasks with slight variations to previous tasks, and the use of lesson sequences where a concept was gradually built upon via a series of tasks. Regarding the repetition of important information, Dane considered that "a lot of repetition is important. If you repeat it, they're hearing the same information". In this sense, repetition of key mathematical points slowed the lesson pace down, emphasizing what was important to students and giving them all "a chance to process it" (Dane 8).

Teachers also recognized the importance of repeating tasks but with a slight variation, such as using different numbers for the same problem structure, as a strategy for consolidating student learning. For instance, Sarah felt that the familiarity of a task structure helped build the students confidence that they would be able to solve the problem. "The fact that they had already seen it, so it wasn't so daunting, and it wasn't too new" meant that students "were able to apply what they learnt from the last lesson to this lesson" (Sarah 3).

Related to the use of task variation to consolidate student learning was the teachers following a sequence of lessons where each new lesson intentionally built upon ideas from the previous lesson:

"Because it was a series of lessons ... It kind of just kept building. And the kids were like, "I know what comes next". So the first day this is really scary. Next day, it's like okay, and the next day they know what to do. Just seeing them really grow in their confidence once they saw it [the mathematics] a couple of times" (Ellen 4)

\section{Discussion}

The aim of the current study was to enhance our understanding of beliefs and reported instructional moves or practices of Foundation to Grade 2 teachers who had participated in a professional learning initiative focused on teaching mathematics through sequences of challenging, problem solving tasks. Given the recognized difficulties teachers have in addressing the diverse needs of learners in the mathematics classroom [1-3], it is imperative that mathematics educators and curriculum designers provide teachers with resources, instructional approaches, and specific teaching practices that they can use to effectively differentiate instruction in their classrooms. Findings of the current study address each of these needs. Two key clusters of findings emerged from our study that have particular relevance to the mathematics education research community.

First, our study suggests that Australian primary teachers perceive presenting the whole class with the same core problem solving task, differentiated through students accessing enabling and extending prompts, as the most effective approach for catering to students of different performance levels in the mathematics classroom. This perception was held by teachers even prior to their participation in the $\mathrm{EMC}^{3}$ professional learning. Although the fact that their schools registered an interest in participating in the $\mathrm{EMC}^{3}$ professional learning initiative means that responses to the pre-program questionnaire cannot be treated as a random sample of early years primary school teachers, this result is extremely encouraging, nonetheless. It implies that the substantial investment in professional learning targeted at teaching mathematics through challenging, problem-solving tasks in Australia led by Sullivan and colleagues $[20,24,26]$ has resonated with a substantial majority of teachers. Moreover, there was evidence that exposure to the $\mathrm{EMC}^{3}$ approach was associated with more negative evaluations of grouping students by a priori perfor- 
mance level in particular. This suggests that teachers who have participated in the $\mathrm{EMC}^{3}$ professional learning initiative hold the view that achieving high quality mathematics instruction for all students is contingent on key components. These include engaging a diverse group of learners in the same core activity, and relying on task design characteristics (e.g., low-floor, high-ceiling; prompts) and teacher pedagogical actions to differentiate the learning experience.

Second, drawing on the Theory of Didactical Situations [45], both to theoretically ground the $\mathrm{EMC}^{3}$ approach and as a lens through which to better understand the range of teacher pedagogical moves necessary for facilitating the approach, proved fruitful. By emphasizing both the a-didactical and didactical components, the Theory of Didactical Situations was able to shed light on how the $\mathrm{EMC}^{3}$ approach emphasizes both student agency and an active role for the teacher. Interviews with teachers revealed that the adidactical components of the approach were critical for supporting the development of norms to encourage student autonomy, through mechanisms such as: providing students with choice over materials, strategies, and methods; employing open-ended, low-floor, high-ceiling tasks; and allowing all students time to struggle independently and think about the mathematics. In a study involving middle school students and their teachers, Hackenberg et al. [1] identified the practice of providing purposeful choices and different pathways to students facilitated differentiated instruction. Unlike the current study, Hackenberg and colleagues used parallel tasks whereby students were presented with two tasks that addressed the same concept but involved different levels of cognitive demand. Students could choose the task they considered a good level of challenge for themselves and worked on the problems in very different ways. The difficulty with this approach, is that the more capable students may not choose the task that is appropriately challenging for them. It also requires teachers to develop multiple tasks for the same concept each lesson. In the $\mathrm{EMC}^{3}$ approach, the open-ended nature of the tasks combined with the low-floor and high-ceiling design, means that only one task is required for the whole class-thus increasing the chances that all students will engage with each task at a greater cognitively demanding level and reducing the workload on teachers.

Teachers also reported employing a variety of intentional, didactical strategies to engage students in the mathematics. Such strategies included: efforts to contextualize the learning to help students make sense of mathematics; using prompts purposefully; and providing explicit opportunities for students to consolidate their learning and make mathematical connections to previous learning. Both the didactical and a-didactical components were supported by teachers possessing beliefs that were also at least ostensibly in tension. On the one hand, interviews revealed that teachers possessed a growth mindset for their students' mathematical learning, placing a premium on allowing students to struggle and valuing challenge, whilst endeavoring to build a community of learners. On the other hand, teachers emphasized the importance of knowing their students as individual learners, in order to determine the level of challenge that might be optimal and how much struggle time to allow. Complementing teachers' beliefs in the importance of knowing their students well was their knowledge of a range of instructional strategies to respond to individual student needs. As acknowledged by Hackenberg et al. [1], the capacity of teachers to respond to student needs in this way is directly related to their willingness to differentiate instruction.

There are limitations of our study that should be noted. First, the interviews conducted did not specifically focus on the instructional aspects that teachers considered worked best for engaging all students in learning mathematics. This point actually adds validity to our qualitative analysis since teachers had no specific prompting during the interview for information about either their beliefs or practices relating to how they differentiated instruction to optimize the learning and engagement of all students in mathematics. However, this also meant that relevant information may have been limited. Future research could use the results of this study to develop an interview protocol that explicitly explores teachers' 
beliefs and practices relating to how they differentiate mathematical instruction to cater for the needs of all students.

Second, we did not conduct classroom observations to confirm the use of specific instructional strategies, instead relying on teacher reporting of their practices and beliefs. It would be important in future research of this nature to complement survey and interview data with classroom observations to see how these practices were enacted and potentially reveal others, that teachers unconsciously used. Finally, our relatively small sample size of 10 teachers from only F-2 classes means that we cannot generalize findings to teachers of upper primary or secondary students. However, our study does complement a growing body of research exploring beliefs and practices of teachers from a range of backgrounds involved in the implementation of differentiated instruction in the context of studentcentered approaches focused on challenging mathematics.

\section{Conclusions}

It is noted that the approach to choosing tasks and structuring lessons advocated by the project represents a change from traditional approaches to teaching mathematics (see, for example, Good, Grouws, and Ebmeier [48]). It is therefore reasonable to conclude that, with appropriate professional learning and resource support, teachers not only see the advantages in terms of building engagement and equity of access but also are willing to embrace and advocate for this approach. This is a critical finding that has implications for curriculum designers, policy makers, and providers of teacher professional learning. It is particularly important given the evidence surrounding the difficulties teachers report experiencing when attempting to implement differentiated instruction [1-3] and the concerns that many voice about the relevance of challenging mathematics for diverse groups of students $[7,18]$.

Author Contributions: Conceptualization of paper, J.B.; conceptualization of overall project, P.S., J.B., A.D. and S.L.; methodology, J.B. and J.R.; formal analysis, J.B. and J.R.; data curation, J.B. and J.R.; writing — original draft preparation, J.B., J.R. and P.S.; writing—review and editing, P.S., J.B., A.D., M.F., S.L. and M.M.; project administration, M.M.; funding acquisition, P.S., J.B., A.D. and S.L. All authors have read and agreed to the published version of the manuscript.

Funding: This research was funded by the Australian Research Council, Catholic Education Diocese of Parramatta and Melbourne Archdiocese Catholic Schools, grant number LP180100611.

Institutional Review Board Statement: The study was conducted according to the guidelines of the Declaration of Helsinki, and approved by the Ethics Committee of Monash University (Project 10791).

Informed Consent Statement: Informed consent was obtained from all subjects involved in the study.

Data Availability Statement: Data is available from the authors on request.

Conflicts of Interest: The authors declare no conflict of interest. The funders had no role in the design of the study; in the collection, analyses, or interpretation of data; in the writing of the manuscript, or in the decision to publish the results.

\section{References}

1. Hackenberg, A.; Creager, M.; Eker, A. Teaching practices for differentiating mathematics instruction for middle school students. Math. Think. Learn. 2020, 1-30. [CrossRef]

2. Holzäpfel, L.; Leuders, T.; Bardy, T. Preparing In-Service Teachers for the Differentiated Classroom. In Proceedings of the 43rd Conference of the International Group for the Psychology of Mathematics Education, Pretoria, South Africa, 7-12 July 2019; Graven, M., Venkat, H., Essien, A., Vale, P., Eds.; PME: Pretoria, South Africa, 2019; Volume 2, pp. 368-375.

3. Maulana, R.; Smale-Jacobse, A.; Helms-Lorenz, M.; Chun, S.; Lee, O. Measuring differentiated instruction in the Netherlands and South Korea: Factor structure equivalence, correlates, and complexity level. Euro. J. Psych. Educ. 2020, 35, 881-909. [CrossRef]

4. Flores, A. Examining disparities in mathematics education: Achievement gap or opportunity gap? High Sch. J. 2007, 91, 29-42. [CrossRef]

5. OECD. The Resilience of Students with an Immigrant Background: Factors That Shape Well-Being; OECD Publishing: Paris, France, 2018.

6. Tomlinson, C.A. Teaching for excellence in academically diverse classrooms. Society (New Bruns.) 2015, 52, 203-209. [CrossRef] 
7. Applebaum, M.; Leikin, R. Mathematical challenge in the eyes of the beholder: Mathematics teachers' views. Can. J. Sci. Math. Technol. Educ. 2014, 14, 388-403. [CrossRef]

8. Stein, M.K.; Smith, M.S. Mathematical tasks as a framework for reflection: From research to practice. Math. Teach. Middle Sch. 1998, 3, 268-275. [CrossRef]

9. Tekkumru-Kisa, M.; Stein, M.K.; Doyle, W. Theory and research on tasks revisited: Task as a context for students' thinking in the era of ambitious reforms in mathematics and science. Educ. Res. 2020, 49, 606-617. [CrossRef]

10. Praetorius, A.; Charalambous, C.Y. Classroom observation frameworks for studying instructional quality: Looking back and looking forward. ZDM Int. J. Math. Educ. 2018, 50, 535-553. [CrossRef]

11. Van de Grift, W.J. Measuring teaching quality in several European countries. Sch. Effect. Sch. Impr. 2014, 25, 295-311. [CrossRef]

12. National Council of Teachers of Mathematics. Principles and Standards for School Mathematics; NCTM: Reston, VA, USA, 2000.

13. Le Donné, N.; Fraser, P.; Bousquet, G. Teaching Strategies for Instructional Quality: Insights from the TALIS-PISA Link Data; OECD Education Working Papers No. 148; OECD Publishing: Paris, France, 2016.

14. Mason, J.; Johnston-Wilder, S. Designing and Using Mathematical Tasks; Tarquin: St. Albans, UK, 2006.

15. Lipowsky, F.; Rakoczy, K.; Pauli, C.; Drollinger-Vetter, B.; Klieme, E.; Reusser, K. Quality of geometry instruction and its short-term impact on students' understanding of the Pythagorean theorem. Learn. Instr. 2009, 19, 527-537. [CrossRef]

16. Sullivan, P.; Bobis, J.; Downton, A.; Hughes, S.; Livy, S.; McCormick, M.; Russo, J. Ways that relentless consistency and task variation contribute to teacher and student mathematics learning. In For the Learning of Mathematics Monograph 1: Proceedings of a Symposium on Learning in Honour of Laurinda Brown; Coles, A., Ed.; FLM Publishing Association: Edmonton, AB, Canada, 2020; pp. 32-37.

17. National Council of Teachers of Mathematics. Principles to Action: Ensuring Mathematics Success for All; NCTM: Reston, VA, USA, 2014.

18. Blazer, D.; Archer, C. Teaching to support students with diverse academic needs. Educ. Res. 2020, 49, 297-311. [CrossRef]

19. Caro, D.H.; Lenkeit, J.; Kyriakides, L. Instructional approaches and differential effectiveness across learning contexts: Evidence from PISA 2012. Presented at the CIES Conference, Washington, DC, USA, 8-13 March 2015.

20. Sullivan, P.; Borcek, C.; Walker, N.; Rennie, M. Exploring a structure for mathematics lessons that initiate learning by activating cognition on challenging tasks. J. Math. Behav. 2016, 41, 159-170. [CrossRef]

21. Vygotsky, L.S. Mind in Society: The Development of Higher Psychological Processes; Harvard University Press: Cambridge, MA, USA, 1978.

22. Dweck, C.S. Self-Theories: Their Role in Motivation, Personality, and Development; Psychology Press: Philadelphia, PA, USA, 2000.

23. Smith, M.S.; Stein, M.K. Five Practices for Orchestrating Productive Mathematical Discussions; National Council of Teachers of Mathematics: Reston, VA, USA, 2011.

24. Sullivan, P.; Askew, M.; Cheeseman, J.; Clarke, D.; Mornane, A.; Roche, A.; Walker, N. Supporting teachers in structuring mathematics lessons involving challenging tasks. J. Math. Teach. Educ. 2015, 18, 123-140. [CrossRef]

25. Sullivan, P.; Mousley, J.; Jorgensen, R. Tasks and pedagogies that facilitate mathematical problem solving. In Yearbook of the Association of Mathematics Educators; Kaur, B., Kapur, M., Berinderjeet, K., Eds.; AME and World Scientific Publishing: London, UK, 2009; pp. 17-42.

26. Hiebert, J.; Grouws, D. The effects of classroom mathematics teaching on students' learning. In Second Handbook of Research on Mathematics Teaching and Learning; Lester, F., Ed.; Information Age: Charlotte, NC, USA, 2007; pp. 371-404.

27. Bobis, J.; Way, J.; Anderson, J.; Martin, A.J. Challenging teacher beliefs about student engagement in mathematics. J. Math. Teach. Educ. 2016, 19, 33-35. [CrossRef]

28. Ingram, N.; Hatisaru, V.; Grootenboer, P.; Beswick, K. Researching the affective domain in mathematics education. In Research in Mathematics Education in Australasia 2016-2019; Way, J., Attard, C., Anderson, J., Bobis, J., McMaster, H., Cartwright, K., Eds.; Springer: Singapore, 2020; pp. 147-175.

29. Cross, D. Alignment, cohesions, and change: Examining mathematics teachers' belief structures and their influence on instructional practices. J. Math. Teach. Educ. 2009, 12, 325-346. [CrossRef]

30. Wilkins, J. The relationship among elementary teachers' content knowledge, attitudes, beliefs, and practices. J. Math. Teach. Educ. 2008, 11, 139-164. [CrossRef]

31. Russo, J.; Bobis, J.; Downton, A.; Hughes, S.; Livy, S.; McCormick, M.; Sullivan, P. Elementary teachers' beliefs on the role of struggle in the mathematics classroom. J. Math. Behav. 2020, 58, 100774. [CrossRef]

32. Russo, J.; Bobis, J.; Downton, A.; Livy, S.; Sullivan, P. Primary teacher attitudes towards productive struggle in mathematics in remote learning versus classroom-based settings. Educ. Sci. 2021, 11, 35. [CrossRef]

33. Richards, J.; Robertson, A. A review of the research on responsive teaching in science and mathematics. In Responsive Teaching in Science and Mathematics; Robertson, A., Scherr, R., Hammer, D., Eds.; Routledge: New York, NY, USA, 2016 ; pp. 36-55.

34. Alfieri, L.; Brooks, P.J.; Aldrich, N.J.; Tenenbaum, H.R. Does discovery-based instruction enhance learning? J. Educ. Psych. 2011, 103, 1-18. [CrossRef]

35. Dooley, T. Constructing and Consolidating Mathematical Entities in the Context of Whole Class Discussion. Mathematics Education Expanding Horizons. In Proceedings of the 35th Conference of the Mathematics Education Group of Australasia, Singapore, 2-6 July 2012; Dindyal, J., Cheng, L.P., Ng, S.F., Eds.; MERGA: Singapore, 2012; pp. $234-241$. 
36. Stein, M.K.; Engle, R.A.; Smith, M.S.; Hughes, E.K. Orchestrating productive mathematical discussions: Five practices for helping teachers move beyond show and tell. Math. Think. Learn. 2008, 10, 313-340. [CrossRef]

37. Stein, M.K.; Grover, B.W.; Henningsen, M. Building student capacity for mathematical thinking and reasoning: An analysis of mathematical tasks used in reform classrooms. Am. Educ. Res. J. 1996, 33, 455-488. [CrossRef]

38. Marshall, J.C.; Horton, R.M. The relationship of teacher-facilitated, inquiry-based instruction to student higher-order thinking Sch. Sci. Math. 2011, 111, 93-101. [CrossRef]

39. Kullberg, A.; Runesson, U.; Mårtensson, P. The same task?-Different learning possibilities. Margolinas, C. Ed. Task design in mathematics education. In Proceedings of the International Commission on Mathematics Instruction Study 22, ICMI, Oxford, UK, 22 June 2013; pp. 609-616.

40. Hershkowitz, R.; Schwatz, B.B.; Dreyfus, T. Abstraction in context: Epistemic actions. J. Res. Math. Educ. 2001, 32, 195-222. [CrossRef]

41. Simon, M.A. Reconstructing mathematics pedagogy from a constructivist perspective. J. Res. Math. Educ. 1995, 26, 114-145. [CrossRef]

42. Yackel, E.; Cobb, P. Sociomathematical norms, argumentation, and autonomy in mathematics. J. Res. Math. Educ. 1996, 27, 458-477. [CrossRef]

43. Ingram, N.; Holmes, M.; Linsell, C.; Livy, S.; McCormick, M.; Sullivan, P. Exploring an innovative approach to teaching mathematics through the use of challenging tasks: A New Zealand perspective. Math. Educ. Res. J. 2020, 32, 497-522. [CrossRef]

44. Russo, J.; Hopkins, S. Teachers' perceptions of students when observing lessons involving challenging tasks. Int. J. Sci. Math. Educ. 2019, 17, 759-779. [CrossRef]

45. Brousseau, G. Theory of Didactical Situations in Mathematics; Kluwer: Dordrecht, The Netherlands, 1997.

46. Artigue, M.; Haspekian, M.; Corblin-Lenfant, A. Introduction to the theory of didactical situations (TDS). In Networking of Theories as a Research Practice in Mathematics Education; Bikner-Ahsbahs, A., Predigrt, S., Eds.; Springer International Publishing: Cham, Switzerland, 2014; pp. 47-65.

47. Braun, V.; Clarke, V. Successful Qualitative Research: A Practical Guide for Beginners; SAGE: London, UK, 2013.

48. Good, T.; Grouws, D.; Ebmeier, H. Active Mathematics Teaching; Longman: New York, NY, USA, 1983. 